\title{
Fracture avulsion of the flexor digitorum profundus tendon. case report
}

\begin{abstract}
In this report, we present a schematic case of deep flexor tendon avulsion of the fourth finger of the left hand. The lesion consists of an intra-articular fracture of the distal palmar portion of the distal phalanx of the fourth finger, resulting in a large bone fragment, which remains incarcerated at the A4 pulley. The diagnosis was retained preoperatively; reinsetion by "pull out" followed by functional reeducation allowed complete functional restoration after 4 months of trauma.
\end{abstract}

Keywords: flexor digitorum profundus, fracture, finger jersey, pull out
Volume 9 Issue 2 - 2019

\author{
Soufiane Aharram, Yahyaoui Mounir, \\ Mohammed Benhamou, Omar Agoumi, \\ Abdelkarim Daoudi \\ Service de Traumatologie-Orthopédie, CHU Mohammed VI, \\ Oujda, Marooco
}

\author{
Correspondence: Soufiane Aharram, Service de \\ Traumatologie-Orthopédie, Faculté de Médecine et de \\ Pharmacie d'Oujda, Marooco, Email aharram.1993@gmail.com
}

Received: March 09, 2019 | Published: March 27, 2019

\section{Introduction}

The traumatic closed fracture of the deep flexor of the fingers is a rare lesion. The first case was described in 1891 by Von Zander. In 1960, Boyes et al., ${ }^{2}$ and Gunter ${ }^{3}$ published the first series. This is a common lesion in young athletes. This is usually an intra-articular fracture of the base of the third phalanx of the fingers where the deep flexor tendon of the fingers is inserted. The mechanism is an upset flexion of a finger followed by hyperextension. Careful clinical examination and special radiographic findings make it possible to retain the diagnosis of tearing of the deep flexor tendon of the fingers, which makes it possible to avoid the therapeutic delay and to improve the functional prognosis there after.

\section{Clinical case}

A 49-year-old right-handed police officer suffered a closed trauma to the fourth finger of his left hand as a result of a fall in his height. He then experienced a violent pain concomitant with a cracking sensation, then an impossibility. active flexion of the distal phalanx. The clinical examination, found a finger slightly edematous, ecchymosed. A flexion attitude of the proximal metacarpophalangeal and interphalangeal joints of the same radius, the IPD was in extension and its active flexion impossible (Figure 1). Simple radiographs of the left frontal and lateral annular hands (Figure 2a, b) have led to the diagnosis of anterior marginal articular fracture of the P3 base.

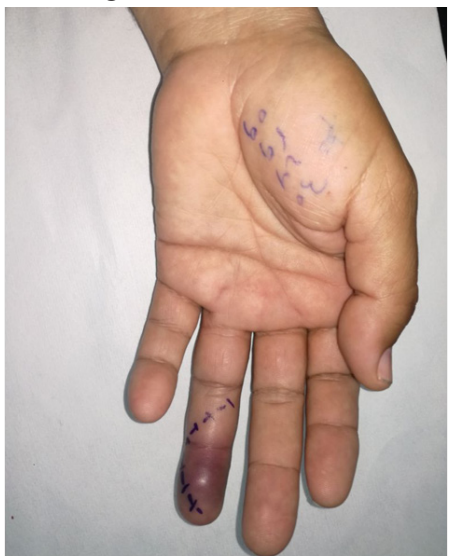

Figure 1 Clinical appearance of the ring finger at the admission of the patient to the emergency.
The operative indication was posed and the intervention performed under locoregional anesthesia and pneumatic tourniquet, with a palmar zigzag approach according to Bruner; the investigation confirmed the displaced anterior margin fracture of the $\mathrm{P} 3$ base, whose reduction and "pull out" fixation enabled the emptiness of the fibrous sheath and distal tendon pulleys (A4, A5) to be demonstrated. FDP (Figure 3).

The bone fragment and tendon were reduced and fixed with an extensible suture attached to a button on the back of the finger by inserting a branch of the suture through the distal fragment (Figure 4). The osteosynthesis was protected by a dorsal immobilization splint kept for four week sallowing passive mobilization by the physiotherapist then the patient began the rehabilitation.
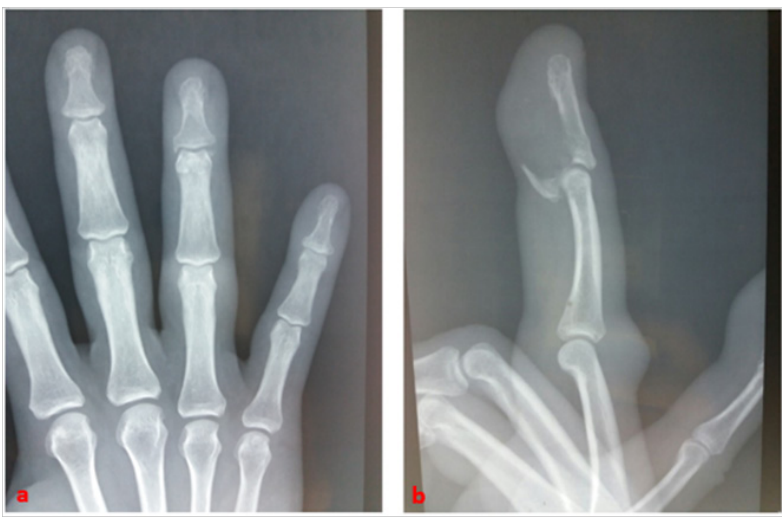

Figure 2a,b Standard radiograph of the front and profile fingers of the annulus confirms fracture tearing of the fragment of the base of the distal phalanx.

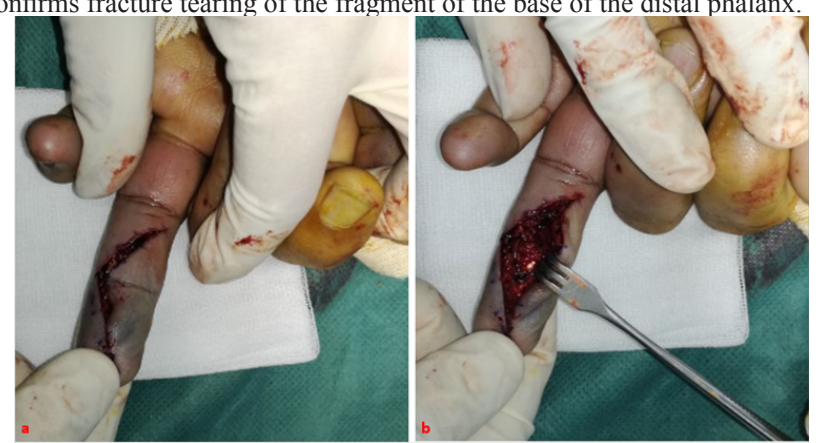

Figure 3a,b Bruner'spalmar zigzag approach confirms the anterior marginal fracture. 

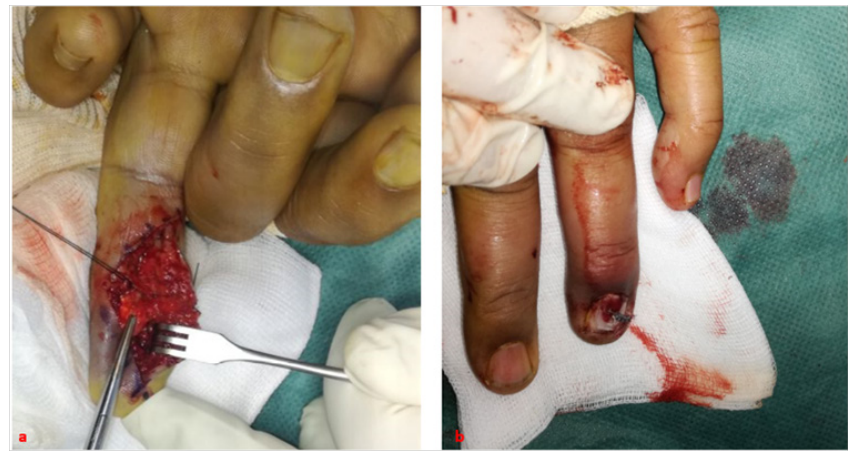

Figure 4a,b Reinsertion of the bone fragment by the technique of "pull out".

In the patient's final evaluation six months after the procedure, the flexion range of the metacarpophalangeal, proximal and distal interphalangeal joints of the injured finger was $90^{\circ}, 90^{\circ}$ and $70^{\circ}$, respectively. The total active movement of the injured finger was $160^{\circ}$, which is excellent for the Strickland and Glogovac criteria ${ }^{4}$ (Figure 5).

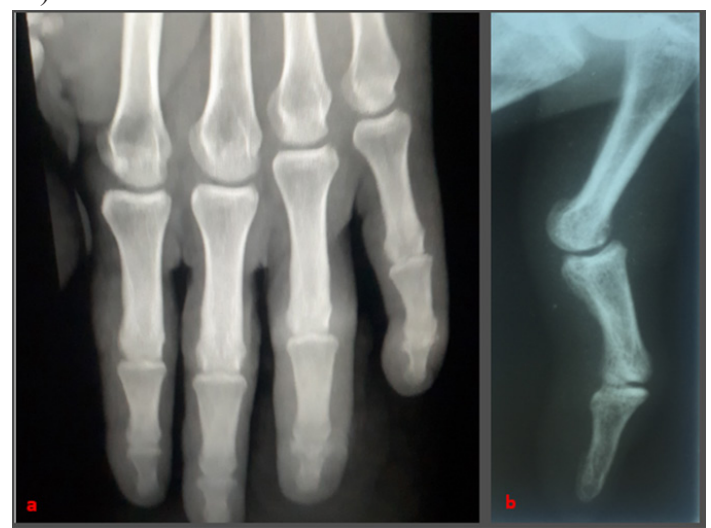

Figure 5a,b Control X-ray at six months of evolution confirms fragment consolidation with good articular congruence.

\section{Discussion}

First described by Boyes et al. in $1960^{2}$, the Jersey finger translated a distal avulsion of the FDP. The traumatic fractures of the deep flexor of the fingers are rare and little known as evidenced by the small number of series in the literature. The diagnosis must be made urgently by a specialist and the treatmentisal ways surgical. Emergency reintegration results in better functional results: $80 \%$ for Mansat and Bonnevialle ${ }^{5}, 100 \%$ for Tropet et al. ${ }^{6}$ and Leddy and Packer. ${ }^{7}$
Regarding the reintegration technique, transosseousre insertion is the mostused and the most reliable. Bunnell's pull-out technique is still widely used, but it tends to be supplanted by micro-brains that have the advantage of their ease of implementation and do not leave externalized material.

If surgical abstention remains the rule in neglected forms and in the sedentary patient, secondary surgical procedures (tendon graft or RPD arthrodesis) may be justified in young motivated manual workers and sportsmen. ${ }^{8}$

\section{Conclusion}

Finger jersey is a pathology of the sportsman, often associated with a fracture of the base of the distal phalanx of a finger. The diagnosis is clinico-radiological, sometimes can go unnoticed.

The evolution is generally favorable if the diagnosis and the therapeutic treatment was early.

\section{Acknowledgments}

None.

\section{Conflicts of interest}

The author does not declare any conflict of interest.

\section{References}

1. Von Zander. Trommler lahmung Inaug. Dissertation, Berlin. 1891

2. Boyes JH, Wilson JN, Smith JW. Flexor tendon ruptures in the forearm and hand. J Bone Joint Surg Am.1960;42-A:637-664.

3. Gunter JH. Traumatic avulsion of the insertion of the flexor digitorum profondus. Aust NZ J Surg.1960;30:1-9.

4. Strickland JW, Glogovac SV. Digital function following flexor tendon repair in Zone II: A comparison of immobilization and controlled passive motion techniques. J Hand Surg Am. 1980;5(6):537-543.

5. Mansat M, Bonnevialle P. Avulsion traumatique du fléchisseur commun profond. À propos de 19 cas. Ann Chir Main. 1985;4(3):185-196.

6. Tropet $\mathrm{Y}$, Nicolet F, Berthoz L, et al. La rupture traumatique des tendons fléchisseurs. À propos de douze observations. Ann Chir Main. 1986;5:59-62.

7. Leddy JP, Packer JW. Avulsion of the profondus tendon insertion in athletes. J Hand Surg Am.1977;2(1):66-69.

8. Tuttle HG, Olvey SP, Stern PJ. Tendon avulsion injuries of the distal phalanx. Clin Orthop Relat Res. 2006;445:157-168. 